\title{
Work Process Based Learning and Serious Games - Didactical Concepts and Objectives for Competency Development
}

\author{
http://dx.doi.org/10.3991/ijac.v8i3.4915 \\ Georg Spöttl, Sven Schulte \\ Institute Technology and Education (ITB), Bremen, Germany
}

\begin{abstract}
Work processes represent an important contentual basis for competency development within contemporary further training approaches in Germany and worldwide. This article underpins this and shows the importance of work process orientation for interlinking learning and working with the aim to develop competencies. At the same time the contemporary technological opportunities open up new forms of learning. Hence a gamification trend is emerging which brings Serious Games approaches to the further training approaches and strategies for personnel development of companies. The article reveals the pedagogical principles behind this approach, some first ideas which have been realized within the framework of a concrete project as well as the didactical challenges which still remain to be tackled.
\end{abstract}

Index Terms-Learning with digital media, work processes, Serious Gaming

\section{WORK PROCESSES AS SUBJECT OF VOCATIONAL EDUCATION}

We can no longer pursue the idea of acquiring skills which will last for a lifetime. A steadily increasing complexity and rapid technological change at the workplace call for competences which respond to changing requirements which we do not yet know.

Consequently we can no longer rely on the mere analysis of the present competencies needed at the workplace and then use this analysis as the basis for designing our training programs. What we need today is a change of paradigms. We need to understand the dynamics occurring because of an increasing complexity and rapid technological progress at the workplace. In order to capture these dynamics we have to unfold the details of any specific work process through a work process analysis.

Any approach of documenting the skills and competences needed at the workplace and then directly deducting training programs from this documentation will be to no avail, because the "half-life period" of many skills is shorter than the cycle of development of the training program. Hence, we can be certain today that learning in the work process at the actual workplace (i.e. the place where all change de facto happens) is the only approach to vocational learning which holds the promise that it brings about competencies for mastering the challenges of work in high-tech occupations.

Guided learning during the work process at the workplace has always been the core of this traditional approach of acquiring the skills needed for successful performance in an occupation. In the past it was rather unlikely that excessive change would happen at the workplace, yet today it is during the work process and right at the actual workplace where unprecedented change happens. Yet, there was no procedure for the verification of the effects of this type of training which came along with the dual system as an ingenious approach to occupational learning. However, this does no longer satisfy our questioning minds and truly we are in a position today that we can "reengineer" learning in the work process by conducting work process analyses and subsequently designing didactical concepts by using Serious Games which help us to identify in detail what is the essence of performing successfully in the work process.

Again: The core of this "re-engineering" of training "in" the work process "for" the work process lies in conducting a series of work process analyses and establishing didactical concepts. If we can define a secure way how to design these didactical concepts and how to establish the Serious Games, we will be able to unfold the essence of acquiring the competences which are needed at the workplace today.

With this basic cognition in mind we can state that we need to conduct work process analyses to generate an insight into the competencies required at the workplace today. When conducting these analyses our concern goes twofold beyond the identification of routine skills - such as using a screwdriver to fasten screws:

First we need to identify "broad" competencies which enable the learner to cope with increasing complexity and rapid change at the workplace and second we need to identify and to convey the domain-specific skills which are basic to what we call a "core work process" in a particular occupation. An example for such a core work process and the corresponding domain-specific skills would be "polishing" for the domain (occupation) of "carpentry", and finally third we need to identify the work process knowledge behind the work processes under scrutiny. The work process knowledge encompasses the theory which is needed for performance in a work process encompassing all aesthetic, moral, societal, and technological aspects.

For the identification of work processes the so-called work process analysis has been developed over the last twenty years in Europe [1] and is used for the identification of the implications of work processes which is relevant for learning in general and for learning within the work processes. Some of the sophisticated instruments which are used for work process analysis are the in-deep- 
discussion with the workers on the work place during the work and the analysis of the action of the worker [2].

However, the identification of relevant work processes and the competencies linked to their mastery do not necessarily mark the end of the efforts of vocational educational research. The next step requires to integrate the findings into a target-group-adequate further training concept. Depending on the framework conditions such as target group, occupation, technical prerequisites and requirements of companies, there is a multitude of didactical shaping options. Since about 20 years, also digital media and their advantages have been made use of. One of the emerging contemporary trends is "Serious Gaming" - an approach which has been pursued in the USA since a longer period of time and which is now also being adopted in Europe and/or Germany. Digital media and their options, enriched by the approach of "Serious Gaming" will be further discussed below. It will be shown that this enhanced approach can also be used in competency development of persons employed in the field of port management.

\section{Digital MediA AND THEIR OPPORTUNITIES - THE APPROACH OF SERIOUS GAMING}

\section{A. Pedgogical-societal context}

From an evolutionary point of view, playing games is already linked to learning processes because rules, experiences or even problem solving strategies are developing during playing although this does not always happen consciously, above all not during childhood. With the increasing institutionalization of education and the frequently clear separation of learning and working, the aspect of learning by playing was overturned. However, in recent times a trend towards "edutainment" is emerging in pedagogy and is enhanced by the new opportunities of the digital media.

Overall there are societal and technological developments which enhance the trend towards the so-called Game-Based-Learning. Thus a "delimitation of the so-far separated social spheres of education, instruction, consumption, and entertainment" is taking place [3].One of the most important factors is seen in the popularity of computer games. The approaches of increasingly networked Game-Based-Learning underline that due to the technological development, the idea of using games (based on digital media) for learning "has recently become the focus of attention with regard to innovations for teaching and learning" [4]. This is also true for new target groups of "digital natives" and their demands for learning [5].

\section{B. Origin and Definition}

Game-Based-Learning per se is not confined to recent media development. It originates in the past centuries when experimental games as a combination of learning and playing as well as matured simulations (e.g. for the training of pilots) came into use. Today we are experiencing the further development: Virtual training worlds or even approaches to Augmented Learning are blended in both the real and the virtual world.

Even if a uniform and generally accepted definition is still inexistent, Serious Gaming represents digital learning games ,which are being applied in occupational initial and further training in order to support conventional learning with the help of technical and multimedia elements" [6]. In contrast Game-Based-Learning enhances the learning processes and is defined as follows: „Game-based learning enables learners to undertake tasks and experience situations which would otherwise be impossible and/or undesirable for cost, time, logistical and safety reasons. Gamebased learning is truly interactive. Everything the learner does, or does not do, has an effect and is thus highly experimental" [7].

On the other hand Prensky set up the combined term of "Digital Game Based Learning". He describes a number of basic requirements in order to successfully implement learning processes within a game. These requirements answer to the terms: "fun, play, rules, goals, interactive, adaptive, outcome/feedback, win states, conflict/ competition, problem solving, interaction, representation/ story" [8].

Altogether the basic question remains how approaches of playful learning can be integrated in different kinds of learning (e.g. implicit and explicit learning) or for the objective of competency development. Is it possible to support transfer options in order to make use of the competencies learning by playing also beyond the world of games? This question inevitably leads to a reflection of didactical principles and the range of playful learning approaches.

\section{DidACTICAL PRINCIPLES FOR GAME-BASED- LEARNING}

From a pedagogical point of view, playing is regarded as a long-term process where near-competitive, performance oriented behavior within moderately difficult game situations is being experienced as entertaining. Longer playing times and a continuous learning process trigger a development in the players ranging from novices to experts.

A basic differentiation is made between a problemsolving and an explorative game approach. Is it rather implicit or explicit knowledge which is imparted during learning? Currently also constructivist approaches are considered, with the aim of self-guidance and a widening of the experience background by playing games. This encompasses situative learning elements, an active learner as well as interaction processes without neglecting informal learning. The overall focus is on competency orientation and on "acting competency oriented to the situative context" [9]. The use of Serious Gaming addresses different learning aspects such as specialist learning, social learning, problem solving or networked thinking and thus relies on "effective and sustainable" learning on a cognitive, emotional, motivational and acting-oriented level [10].

Competences which can be used for problem-solving come to the fore when there are problems within the work process. The acquisition of competencies itself is achieved by multiple playing sessions. Experiences acquired during multiple playing sessions generate an increasingly more complex mental image of the game which is reflected by the corresponding competencies of the learner [11]. The acquisition of competencies is taking place in the form of a cycle: one's own "behavior" gets feedback by the game. This feedback is then evaluated by the learner, success is enhanced and knowledge, acting and competencies are 
developed in a target-oriented way depending on the complexity of the game [12].

Another central component is motivation which forms a basic prerequisite (which is normally given during playing). However, the game only becomes effective as soon as an immersive game design offers an entertaining and inspiring experience. The well-known "Flow-Effect" is also an element of playful learning as the learners delve into the game and experience a clearly positive feeling of success. However, learning and playing need adequate framework conditions (and a "playful attitude" and/or "stance of playfulness"). The flow experience or immersion relates to focusing on the medial contents [13].

In order to achieve learning progress and to reach the learning objectives it is also necessary to engage in (self)reflection processes. This has to be encouraged and supported by the teaching staff. The mechanisms behind it, such as feedback, help and the explanation of rules, are the central elements of success of a game featuring the necessary balance of difficulty and challenge.

Another point is the differentiation between "serious" and rather "funny" learning intents. From a didactical perspective it is important to be aware of the extent of "serious" playing and learning intents. Thus the risk is minimized to commit oneself to the gamification trend and to avoid likely false expectations with regard to an educational game. In his Keynote Address on the occasion of ICELW 2015, Ian Bogost, discussed e.g. the difference between Game Design (for Serious Games) and Gamification and presented seven principles underpinning this antagonism [14].

In spite of all good pedagogical approaches the range of application of learning games has still to be discussed. Is a game still a game when it is being didactically instrumentalized? As a rule, three variants are possible when it comes to the connection of real situations and didactically shaped learning situations [15]: 1) The game and the application situation are more or less congruent. A direct transfer of learning experiences is feasible; 2) An application situation can be embedded into a didactically shaped learning situation and thus enables reflection processes; 3) The game is equipped with learning tasks without a link to a real application situation. "Just" the game flow and a general learning progress are achieved.

Behind this discussion one of the latest paradigms of learning can be identified, the paradigm of life-longlearning. Within this paradigm the person who is learning is in the center of the learn process. He or she has to deal with the practical requirements of a work process and to make use of any approaches, e.g. games, to support learning and to reflect deeply about the practical issues for using the outcome of this learning process for one of the next new work periods. As for the "worker" and "learner" in the work process this requires a kind of self-directed shaping of work environment to bring together work requirements and learning supported by a game approach. This needs not only high motivation of the worker. The worker has to be convinced of the advantage of learning within the work process and companies have to accept learning within working as an important issue to enhance quality.

The current empirical findings reveal a heterogeneous answer to the question about the effects of games for educational purposes. The corresponding discourses deal with transfer options, but also with the dependence of the learning success from e.g. learning types, learning and playing experiences or the individual media used. In principle this young field of application is still calling for more research work.

\section{PRACTICAL EXAMPle: SERIOUS GAMING FÜR SKILLED WORKERS IN PORT AUTHORITIES}

The research project ArKoH ${ }^{1}$ (Arbeitsprozessorientierte Kompetenzentwicklung für den Hafen der ZukunftWork process oriented competency development for the port of the future), a Serious Game is being developed and tested in cooperation with skilled workers for two fields of application: On the one hand the project focuses on work processes for the logistics of offshore components and on the other hand on logistics processes for container. In the first case of application the work flow is very variable and can only be realized with a lot of personnel that has to be partly highly specialized. There is a multitude of preparatory measures and continuous controls are being conducted within the loading process in terms of quality and work safety. In connection with the dependency on weather conditions and logistical imponderabilities (availability of ships, industrial trucks and personnel) very complex and flexibly manageable processes are created. On the contrary, the area of container logistics has already reached a high grade of standardization and automation. The requirements for the staff - above all the necessary qualifications - are not highly developed and existing deficiencies can mostly be compensated without problems. Compared to the complex planning and problem-solving competencies of offshore logistics, work safety and quality checks are more important. These two explicitly chosen and different fields of application are meant to show the chances and opportunities for the shaping of a Serious Game in a sector which will have to tackle the menace of a lack of skilled workers in the near future, due to the age structure of the personnel.

\section{CURRENT RESULTS AND OUTLOOK}

The current results of work process analyses and the development of didactical specifications for the Game Design and for the curriculum shows that a number of requirements regarding the contents are emerging. At the same time new aspects have to be considered. The core of the learning contents which should be imparted in a process oriented way and with the aid of real work tasks is composed of the following competences:

- Maritime English

- Coordination of the shipping process with the team (foremen, surveyor, skilled worker for logistics at the port authority)

- Selection and use of the correct fixing devices of cargo

- Identification of deficiencies of fixing devices

- Choice and handling of industrial trucks

- Knowledge and application of safety regulations for transportation on the port area

\footnotetext{
${ }^{1}$ The project is supported by funds of the Bundesministerium für Bildung und Forschung - BMBF (German Federal Ministry for Education and Research).
} 
- Knowledge and application of regulations for work safety on the port area

- Application of different storage techniques

- Knowledge of physics (e.g. weights, agents, understanding load diagrams, statics)

- Understanding and use of visible indicators

- Quality check of loaded goods (for tower segment, blades, monopile, container

- Documentation of the shipping order.

Apart from the above mentioned competences, further competences were identified which are, however, difficult to process for a Serious Game. The requirement of working according to varying weather conditions, the communication via wireless or the ability to work in a team cannot be integrated into the design of a game.

The shaping of a game in terms of contents is oriented towards a curriculum which describes the mentioned competences in different levels of difficulty. At the same time it will consider the individual working steps of work processes and with the different roles of the employees (management level, skilled workers, and operators).

Altogether companies must consider whether the use of Serious Games has an effective and sustainable impact on learning effects. "The intention to use digital games for educational purposes represents a great challenge for the instruction and game design as an imbalance of pedagogical requirements and game technological realization leads to results which are neither instructive nor entertaining" [16] At the same time, high pedagogical demands also trigger a number of ambivalent expectations and apparent contradictions, e.g.: open exploration vs. fixed curriculum? Complexity vs. costs? Motivation vs. learning acts? Fun vs. learning? The evaluation of the mentioned project and the exchange with other research project s within the context of Serious Gaming will try to find answers to the questions - also with a view to the option to link real work processes with modern further training approaches supported by digital media.

\section{REFERENCES}

[1] Spöttl, G.; Becker, M. (2013): Standards for Teacher Training in Technical and Vocational Education (TVET) Fields of Study. In: Schröder, Th. (Ed.): Vocational Teacher Education and Research as Task and Challenge for the East and Southeast Asian Region. GIZ, Voctech, UNESCO Bangkok, Shanghai, 2013, p. 28-31.

[2] Becker, M.: Handlungsorientierte Fachinterviews. In: Rauner, F. (Ed.): Handbuch Berufsbildungsforschung. Bielefeld: W. Bertelsmann Verlag, 2005, p. 601-606.
[3] Rauschenbach, T.: „Konzeptionelle Grundlagen für einen nationalen Bildungsbericht - nonformale und informelle Bildung im Kindes- und Jugendalter", Berlin, 2004.

[4] Breuer, J.: ,Spielend Lernen? Eine Bestandaufnahme zum (Digital) Game-Based-Learning“, LFM Dokumentation Band 41, 2010, p. 7.

[5] Prensky, M.: „Digital game-based learning“, St. Paul Paragon House, 2007.

[6] Feist, M. and Franken-Wendelstorf: „Informelles Lernen und der Einsatz von Serious Games", In: Metz,M. and Theis, F.: "Digitale Lernwelt - Serious Games. Einsatz in der beruflichen Weiterbildung", pp. 69-76.

[7] Corti, K.: "Serious Games". In: Learning Magazine, 2005.

[8] Franke, G.-P.: "Game-Based-Learning. Darf Lernen auch Spaß machen?" In: Metz,M. and Theis, F.: "Digitale Lernwelt - Serious Games. Einsatz in der beruflichen Weiterbildung", p. 53-62.

[9] Erpenbeck, J. and von Rosenstiel, L.: „Handbuch Kompetenzmessung. Erkennen, Verstehen und Bewerten von Kompetenzen in der betrieblichen, pädagogischen und psychologischen Praxis", Stuttgart, 2003.

[10] Schaub, H. and Bucher, L.: „Trainieren für den Einsatz: Serious Games als Trainings-, Ausbildungs- und Lernmedium im Umfeld Verteidigung und Sicherheit", In: Metz,M. and Theis, F.: "Digitale Lernwelt - Serious Games. Einsatz in der beruflichen Weiterbildung", S. 109-116.

[11] Gariss, R. at al.: "Games, motivation and learning. A research and practice model", Simulating Gaming, 33(4), p. 441-467.

[12] Prensky, M.: „Digital Game-based learning“, Comput Entertain. $1(1)$, p. $1-21$.

[13] Krämer, N.C.: „Mensch-Computer-Interaktion“. In: Mangold, P. et al: „Lehrbuch der Medienpsychologie“, Göttingen, Hogrefe, 2004, pp. 643-671.

[14] Bogost, I.: "Gamification vs. Game Design: What's the Difference?”. Opening Keynote. ICELW 2015. New York.

[15] Kerres, M; Bormann, M. and Vervenne: „Didaktische Konzeption von Serious Games: Zur Verknüpfung von Spiel- und Lernangeboten“, Zeitschrift für Theorie und Praxis der Medienbildung, 2009.

[16] Ibid, p. 5.

\section{AUTHORS}

Dr. G. Spöttl is Professor and Director of the Center for Technology, Work and TVET at UBC, University Bremen, Universitätsallee 19, 28359 Bremen, Germany. (e-mail: spoettl@uni-bremen.de).

Sven Schulte is Senior Researcher in the Institute Technology and Education (ITB) at the University of Bremen, Am Fallturm 1, 28359 Bremen, Germany. (e-mail: sven.schulte@uni-bremen.de).

This work is supported by funds of the Bundesministerium für Bildung und Forschung - BMBF (German Federal Ministry for Education and Research). Manuscript received 31 July 2015. Published as resubmitted by the authors 30 August 2015 . 